\title{
O "MUNDO VERDADEIRO" SE TORNOU FINALMENTE NOTÍCIA: Tecnologias de Comunicação, Niilismo e Pós-modernidade
}

\section{The "real world" has finally become news: technologies of information, nihilism and post-modernity}

RESUMO: $O$ presente artigo se interroga a respeito da possibilidade de uma experiência ética após o advento do Niilismo. Para tanto, buscou-se relacionar o conceito de niilismo com uma modificação da condição de sujeito a partir de sua relação com a verdade, com a temporalidade e com o progresso histórico das civilizações. Em um primeiro movimento, tentou-se caracterizar esses eixos tal como se deram na Modernidade clássica a partir da compreensão de um sujeito do conhecimento a quem caberia desvendar a verdade do mundo, bem como de uma temporalidade que se moveria sempre à frente na busca de um maior progresso e autoconsciência das civilizações. Em seguida, intentou-se caracterizar de que modo o desenvolvimento das tecnologias de comunicação, assim como das ciências humanas, fraturam essa experiência da Modernidade e produzem o que Nietzsche nomeou como Niilismo. Ao relacionar o Niilismo como traço inaugural de uma pósmodernidade, desejou-se caracterizar essas modificações orientando-se para uma possibilidade de uma experiência ética contemporânea.

Palavras-chave: Filosofia. Niilismo. Pós-modernidade. Tecnologias de comunicação. Ética.

ASBTRACT: The present article wonders about the possibility of an ethical experience after the emergence of Nihilism. In order to achieve this purpose, we tried to relate the concept of nihilism to a change in the condition of the subject regarding its relation to the truth, with temporality and the historical progress of civilizations. In a first movement, we tried to characterize these axes as they were shaped in classic Modernity from the comprehension of the subject of knowledge who should be the one to unveil the truth of the world, as well as the temporality which would always move forward in search of a higher progress and self-consciousness of civilizations. After that, we intended to characterize in which way the development of communication technologies, as much as that of the Human Sciences, rupture that experience of Modernity and produce what Nietzsche named as Nihilism. At relating Nihilism as opening trace of a post-modernity, we desired to characterize these changes guiding ourselves to the possibility of a contemporary ethical experience.

\footnotetext{
${ }_{1}^{1}$ Mestre em Filosofia pelo Programa de Pós-graduação em Filosofia da Universidade Federal do Piauí. Graduado em Letras - Inglês pela UFPI. E-mail: ayres-thiago@hotmail.com
} 
Key-words: Philosophy. Nihilism. Post-modernity. Communication Technologies. Ethics.

\section{Introdução}

A Filosofia sempre tentou se colocar os problemas que acreditava serem decisivos para a compreensão do ser do homem. As diferentes formas de se elaborar tais questões derivavam das diferentes avaliações do que seria decisivo à condição humana tal como pensada em diferentes momentos da civilização. Assim, dentro dessa perspectiva, todo pensamento filosófico se aproxima de algum modo a uma Ontologia. No atual estágio de nossas civilizações ocidentais globalizadas, a tecnologia em todas as suas faces se tornou uma tal questão decisiva. É diante desse problema que diversos trabalhos filosóficos, que partem das mais variadas teorias, se voltam para diferentes questões e implicações do mundo tecnológico em campos tradicionais da Filosofia como a Ética, a Estética, a Política etc.

Dessa forma, esse artigo visa se inserir em uma discussão bastante ampla ao abordar especificamente o problema das tecnologias de informação em massa, ou mass media, e a possibilidade de uma experiência da história que poderia ser chamada de pós-moderna. Para tanto, buscar-se-á caracterizar a típica experiência histórica da Modernidade "clássica", concebida aqui como aquele período que se inicia no século XV e se estende até meados do século XIX, para melhor avaliar o alcance das modificações causadas pelas tecnologias de comunicação e decidir se faz sentido ou não criar uma demarcação que diferencie essa nova experiência histórica daquela mais estabelecida, equivalente à Modernidade.

A partir daí, serão questionadas as formas como se dão essas novas experiências históricas que caracterizam uma sociedade midiatizada. Para além dessa intenção de mapeamento, esse artigo tem como seu objetivo apontar, ainda que inicialmente, novas formas de experiência ética a partir dessas modificações apresentadas na forma como nos relacionamos com a história. Se o mesmo conseguir elaborar uma indicação nesse caminho, terá alcançado o seu objetivo.

\section{Experiência histórica da Modernidade Clássica}


Para se pensar a experiência histórica da Modernidade, ou seja, a forma como essa época compreende a sua relação com uma ideia de historicidade, podese começar apontando que a Modernidade é o momento histórico por excelência da civilização Ocidental (VATTIMO. 1992. p.VII), em oposição a uma compreensão cíclica do mundo que caracterizaria momentos anteriores. Essa historicidade moderna se apresentava como uma colocação explícita do problema da história. Assim, podemos apontar que foi através da sua própria autoconsciência e, ao mesmo tempo necessidade de autocompreensão e autocertificação que o pensamento moderno se inquiriu sobre o papel da história na determinação de uma característica distintiva da Modernidade em relação aos demais estágios da civilização ocidental (HABERMAS. 2002. p.12).

Já no século XVIII, é possível encontrar o uso da expressão "tempos modernos" em textos, tanto na Alemanha, como na França e na Inglaterra (KOSELLECK apud HABERMAS. 2002. p.09). Essa expressão era utilizada para se referir aos três séculos anteriores que apresentavam, desde seu marco inicial em 1500, uma drástica mudança, pois indicava "uma época orientada para o futuro, que está aberta ao novo que há de vir" (IBIDEM). Assim, o pensamento moderno abre-se mesmo para uma noção explícita de temporalidade, de que é preciso um contínuo avanço histórico para o prosseguimento do caminhar histórico. É dessa forma que a Modernidade vai ter como um de seus conceitos mais importantes a Superação de um momento histórico anterior (VATTIMO. 1996. p.IX). Para que possamos entender sob qual critério se dará essa superação é preciso analisar um outro aspecto central da Idade Moderna que se encontra intimamente relacionado com 0 aspecto anteriormente mencionado.

A Modernidade se distanciou do período que a precedeu por um imenso ganho de informações sobre o seu passado. Durante o Renascimento, há uma reapropriação de boa parte do pensamento clássico através das traduções que chegavam a Europa vindas do mundo árabe. É nesse período também que as ciências matemáticas conhecem um intenso aflorar, tornando-as uma espécie de saber fundamental que legitimaria as demais conquistas científicas, produzindo assim o que Habermas, seguindo uma interpretação que se tornou clássica em Max Weber, afirma ser uma necessidade moderna de encontrar a legitimação de suas práticas estéticas, políticas etc em si mesma e não com recurso ao que lhe foi legado pela tradição (HABERMAS. 2002. p.12). Desse modo, é durante o século 
XVII e XVIII que podemos constatar um intenso processo de racionalização das estruturas sociais que, por sua vez, pode ser relacionado com um processo mais geral de laicização cultural que deriva da aceitação do lluminismo e da postura democrática derivada da Revolução Francesa.

Nessa conjuntura, a superação de um momento histórico para outro se dará sempre como um ganho reapropriativo da razão em relação à situação do homem na História. Esse ganho reapropriativo se legitimará como uma recuperação de um princípio que possibilita uma melhor fundamentação do pensamento sobre a condição do Homem e, por conseguinte, uma melhor estratégia de práticas política que vise à realização de processos emancipatórios. Destarte, era como uma fé no potencial emancipador da razão que se fundamentavam as formas de prática política; era o sujeito centrado nessa razão que ocupava a posição de sujeito político da história, uma vez que era através desse esclarecimento que o mesmo deveria abordar as questões éticas que, em última instância, reverberariam na situação política (VATTIMO. 1996. p.VI-VII).

Assim descrita a Modernidade no que concerne à sua experiência da História, cabe apontar que o que condicionava essa mesma experiência era a noção de que havia um centro para essa história que avançava em relação a um maior progresso e que conduziria, finalmente, para a total realização desse sujeito da História (VATTIMO. 1992. p.08). Esse centro foi indubitavelmente a civilização iluminista europeia. Entretanto, a partir do final do século XIX essa compreensão que a Modernidade tinha de si mesma passa a se tornar cada vez mais difícil de ser sustentada. Isso se dá por diversos fatores, um dos quais, aquilo que se coloca como interesse focal desse trabalho, a saber, o desenvolvimento das tecnologias de comunicação.

\section{Mass Media, Niilismo e Pós Modernidade}

Para se compreender a relevância das tecnologias de comunicação na modificação da experiência histórica das civilizações ocidentais, é preciso relacionálas com as ciências humanas, aquele grupo de saberes que busca constituir uma descrição positiva da situação do homem com base naquilo que ele fez de si mesmo (IBIDEM. p.19-ss). Como aponta Gianni Vattimo, a relação dessas duas atividades está muito mais imbricada do que pareceria à primeira vista, pois para que haja a 
possibilidade daqueles saberes que são denominados "ciências humanas" é preciso primeiro algum grau de refinamento dos meios de coleta e transmissão de informações. A Sociologia precisou que uma coisa como o "social" fosse determinada antes que pudesse lançar no projeto de descrevê-lo e interferir com o mesmo. Para tanto, foi necessária uma forma de definição de um comportamento coletivo que satisfizesse aquela definição de "fato social". Essa relação fica ainda mais evidente quando se pensa na Antropologia, pois essa seria impossível sem a possibilidade do confronto com outras civilizações e os mecanismos de coleta de informação a respeito das mesmas.

Assim, o avanço das tecnologias de comunicação permitiu o aprofundamento das atividades dessas ciências de modo a intensificar o confronto daquela civilização moderna que, até meados do século XIX, ainda acreditava com bastante convicção ser o destino de toda e qualquer forma de humanidade. Esse confronto conduziu paulatinamente a uma instabilidade nos grandes ideais da Modernidade, como aquele da história universal, da História enquanto progresso rumo a uma total realização da humanidade, pois, como aponta Walter Benjamin em suas Teses sobre o Conceito de História (1940), pensar a história como um continuum é levar em consideração apenas a perspectiva daqueles que formam o "cortejo triunfal", daqueles que construíram a sua história a despeito do esquecimento da história de infindáveis grupos de derrotados (BENJAMIN. 2012. p.244).

Para além dessas implicações das tecnologias de coleta e transmissão de dados na desconstrução daquela ideia de história tão cara à Modernidade, há ainda um outro impacto que caracteriza ainda mais drasticamente uma ruptura causada por essas tecnologias e a experiência moderna da historicidade. Trata-se da realização uma tanto "perversa" da autoconsciência desejada pela modernidade através de um ideal de "Sociedade Transparente" (VATTIMO. 1992. p.10-ss). Esse ideal pode ser pensado como o desejo de uma total realização do Espírito Absoluto hegeliano, onde a civilização ocidental estaria completamente consciente daquilo que the constituiria.

Desse modo, ao invés de o desenvolvimento exponencial das tecnologias de informação tornar uma sociedade mais "esclarecida" tal como pensava ainda Hegel e mesmo Marx com a ideia de um fim da ideologia, o que esse processo trouxe à tona foi uma vasta complexidade e variedade de visões de mundo (IBIDEM. p.11). A importância de tal surgimento dessas diferentes Weltanschauungen não foi somente 
a possibilidade de se reconhecer outras identidades fortes que não eram levadas em consideração quando a Modernidade pensou a si mesma, mas antes, uma evaporação dessas mesmas identidades que apontou a inessencialidade de cada uma delas, naquilo que Vattimo chama de desenraizamento (IBIDEM. p.15).

Um terceiro aspecto em que se mostra a importância dos mass media para a definição de uma experiência histórica característica das sociedades capitalistas avançadas é o caráter de contemporaneidade das mesmas. A contemporaneidade não é aqui compreendida meramente como aquilo que está mais próximo de um ponto de vista cronológico, mas a possibilidade que se apresenta de um "tomar conhecimento" de eventos no momento mesmo de sua realização. Esse processo teve sua primeira possibilidade nas transmissões ao vivo à rádio, depois a TV e por fim, encontram-se largamente exploradas pela Internet (VATTIMO. 1992. p.24). Dessa maneira, pode se apontar que houve uma total imbricação entre os eventos e sua narratividade que fragilizou a importância de uma realidade objetiva que estaria além de toda e qualquer descrição feita dela, que fundiu essa realidade com a interpretação que dela se dá, tornando profética a crítica de Friedrich Nietzsche ao conceito mesmo de "verdade" como adequação da representação do sujeito ao objeto, pois essa noção mesma de sujeito-objeto se tornou apenas uma possibilidade de interpretação entre outras (NIETZSCHE. 1999. p.108-110). Assim, para ficarmos ainda nas "previsões" nietzschianas, é que "o mundo verdadeiro se tornou fábula" (IDEM. 2013. p.31-33), pura narratividade.

Dessa forma, pode-se perceber que as tecnologias de comunicação não são apenas um aspecto periférico das sociedades pós-industriais, mas configuram um aspecto central das mesmas e para a constituição ontológica daqueles que as habitam. É por isso que se pode, tendo por base a experiência histórica característica da modernidade e sua modificação dramática frente aos mass media, falar de uma ruptura com a modernidade e do início de uma era pós-moderna. Além dessa distinção, a modificação do estatuto da objetividade, principalmente através da diluição da imperatividade da realidade em suas possibilidades narrativas e interpretativas, pode-se acrescentar que essa pós-modernidade carrega o traço daquilo que Nietzsche chamou de Niilismo. Uma das faces do Niilismo parece ser uma total paralisação do pensamento, seria necessário equivaler a pós-modernidade definida nos termos acima como o momento de fim da filosofia ou mesmo do 
pensamento? Ou seria essa a oportunidade para se construir uma nova forma de pensa?

\section{Pensamento e Experiência Ética na Pós-modernidade}

Se aquilo que Nietzsche chamara de Niilismo é o que instaura uma situação verdadeiramente pós-moderna no pensamento, é precisamente no seio de sua reflexão sobre esse conceito que se podem encontrar as possibilidades de abertura que o diferem genuinamente daquele que o precedeu, a saber, o pensamento da Modernidade clássica. Para tanto, é preciso apontar de que forma Nietzsche relaciona 0 ato do pensamento com o conceito de Niilismo e apresentar que, ao mesmo tempo em que esse termo apresenta a impossibilidade de uma forma de pensamento, é nele mesmo que se encontra a chance de um outro.

Para a filosofia de Nietzsche, a atividade do pensamento não é meramente uma contemplação dos atributos da "realidade empírica" na busca de uma compreensão de suas categorias estruturantes, mas sim uma atividade criadora que está submetida a certos valores que se constituem como necessários para a manutenção de uma determinada forma de vida (NIETZSCHE, 1992, p.117-118). Nesse contraste apresentado, temos duas formas distintas de pensar: a primeira caracteriza aquele pensamento tradicional da filosofia, um pensamento que se quer descritivo, o pensamento da Modernidade que foi dominado pelo campo da metafísica; já a segunda, apresenta o pensamento que desconfia do caráter de objetividade que o pensamento metafísico atribuía a si mesmo, e passa a entender o ato de pensar como uma criação interpretativa que encontra seus "fundamentos" (ainda que o termo não tenha mais a força que tinha na tradição metafísica) engajados com a preservação de certos modos de existência.

O niilismo trouxe uma desconfiança quanto ao alcance dessa primeira forma de pensar ao evidenciar a dificuldade estrutural que o conceito de Verdade impõe a si mesmo. Portanto, Nietzsche apresenta o como uma das faces do Niilismo aquele que ele denomina Nilismo passivo, uma postura que pode ser ilustrada por aquelas doutrinas que se constroem a partir de um fundamento que seria sólido e objetivo, do qual a vontade criadora do espírito está ausente. Ironicamente, podemos considerar exemplos dessas teorias duas construções que ficaram famosas por seu caráter de "suspeita", a saber, a Psicanálise e o Marxismo, que em alguns 
momentos foram colocados lado a lado com o próprio pensamento nietzschiano em sua vocação desmitificadora.

Por sua vez, o Niilismo ativo se apresenta como aquele pensamento que adotou o Perspectivismo dentro de si; um pensamento que não se entende como definitivo por saber que suas "bases" são os dependentes de um jogo de forças que nunca cessa; que possui diferentes pontos de harmonização hierárquica que estão sempre se modificando. Esse pensamento se dá, portanto de modo transitório. Essa transitoriedade leva a um outro aspecto central do Niilismo ativo: sua plasticidade. Um pensamento como esse precisa cultivar uma moderação da qual Nietzsche fala e que não deve ser confundida com aquele caminho do meio do qual fala Aristóteles (VATTIMO. 2010. p.249). Essa moderação concerne à capacidade de sobrevivência ao confronto com todo evento que destruiria as estruturas mais caras a um modo de pensamento, um pensamento que daria mesmo o lugar para o contraditório ou mesmo insondável. É por isso que nos seus últimos escritos, é com a arte e o artista que Nietzsche apontará uma maior proximidade com essa forma de pensar.

É nessa segunda forma de Niilismo que a pós-modernidade encontra uma possibilidade de gerar uma nova relação entre história e pensamento e, a partir daí, uma nova forma de um pensamento ético que não carregue aqueles ideais de esclarecimento e emancipação que carregam a marca da Modernidade. Uma vez que no niilismo característico da pós-modernidade o "mundo verdadeiro se tornou fábula", para retomar a expressão de Crepúsculo dos ídolos mencionada anteriormente, a experiência com a verdade não passa a ser mais imperativa ou coerciva, pois a mesma sempre está vinculada a um caráter de criação narrativa. É por isso que Nietzsche pensará a arte como uma nova forma de relação com a verdade, pois a "realidade externa" não poderá mais ser pensada sem a sua imbricação com os investimentos da imaginação daqueles que a "interpretam". É por isso que Gilles Deleuze dirá que, a partir de Nietzsche, a filosofia não mais se ocupará da adequação de uma teoria, mas da perspectiva que aquela teoria, enquanto "fábula", narração, implica, se uma perspectiva vil ou nobre (DELEUZE. 2006. p.175).

É Deleuze também que aponta, seguindo aqui várias indicações das últimas obras de Nietzsche, uma forma que se movimenta juntamente com aquela que vê na arte a sua referência. Trata-se da compreender a filosofia como sintomatologia ou semiologia (IDEM. 2018. p.11-12). Assim, é com essa referência que a filosofia deve 
encarar os acontecimentos, buscando efetuar uma crítica imanente dos mesmos, de forma a se conceber que forças condicionam uma determinada interpretação/apresentação de um acontecimento de uma forma específica.

Dentro desse mundo da comunicação generalizada, as coisas (um objeto, conceito, acontecimento), não devem ser pensadas como aparência sob a qual se esconde a essência, ou como aparição, mas como sintomas que apontam para modos de ser que avaliam segundo as suas próprias exigências para a manutenção daquilo que se thes apresenta como necessário. No desenvolvimento de sua obra Nietzsche e a Filosofia (1962), Deleuze afirma que a projeto mais geral do pensamento nietzschiano era introduzir os conceitos de sentido e valor na filosofia, de forma a transformá-la em uma crítica radical. Essa crítica se caracterizaria precisamente por uma atividade genealógica que visaria esclarecer o sentido das coisas, relacionando-os com os valores que fundamentam as interpretações que Ihes atribuem esses sentidos, e que encontram sua própria fundamentação em formas de apreciação relacionadas com modos de ser. A esses de modos de ser, essas avaliações que constituem o sentido das coisas ou, ainda, que constituem as coisas mesmas Deleuze chamará força, que aqui, não deve ser compreendida como coisas externas ao objeto, mas como tendências interpretativas que se apoderam de algo para the dar mais um significado. Assim, uma coisa terá tantos mais significados quanto mais modos de ser se apoderarem dela.

Esse procedimento, que de alguma forma se aproxima de uma perspectiva de "crítica da ideologia", acabou por produzir um enfraquecimento do caráter central do sujeito como lugar da verdade, mesmo quando pensada em verdade de si. Pois, se essa crença se sustentava na pretensão de que a consciência era capaz de produzir uma representação objetiva da realidade (essa sendo uma das características mais marcantes do pensamento moderno), a própria consciência, quando confrontada com os métodos investigativos desenvolvidos no seio de seu desenvolvimento histórico, se apresenta como algo dotado de muitas camadas que a constituem. Há uma série de fatores, como exigências históricas, confronto e acomodação de várias crenças "não-demonstradas" que subjazem a sua construção. Assim, essa crença se mostra apenas como mais uma interpretação, uma fábula ou narração que não encontra suas bases senão em um sistema de valores que são considerados essenciais por um modo de ser específico, que não carrega em si os princípios da vida, mas apenas de sua própria vida (NIETZSCHE. 2011. p.247-250). 
Produz-se também uma modificação da experiência ética, uma vez que, diferentemente de como pensavam parte dos filósofos modernos, não é possível referir uma ação livre a uma representação objetiva da realidade. É necessário concluir, portanto, que a pós-modernidade definida nos termos de uma sociedade de comunicação generalizada deve conduzir necessariamente ao fim da possibilidade de uma experiência ética? Provavelmente não. Antes, há uma abertura de se pensar a ética em outros termos. O agir ético não será pensado como uma decisão deliberada de um indivíduo, mas como a construção de modos de ser (avaliações, como afirma Deleuze) que apresentem uma maior abertura para a multiplicidade, um processo que Vattimo chamou de "arte da oscilação" (VATTIMO. 1992. p.51). Nessa nova configuração, o agir individual não é mais aquilo do que depende o destino da humanidade ou daquele que age, mas antes, uma peça na constituição de uma máquina, ou de uma obra de arte (DELEUZE. 2006. p.326-ss), que saiba viver uma existência superficial (VATTIMO. 2010. p.297), no sentido de saber-se jogo.

\section{Considerações Finais}

Assim, ainda que numa perspectiva provisória, esse trabalho espera ter apontado que as modificações que os meios de comunicação de massa produziram na experiência histórica e ética da modernidade não necessariamente causaram uma falência de toda e qualquer possibilidade ética (ou mesmo política, pois ambas estão relacionadas de alguma forma); mas apresentaram a necessidade de se estabelecer novas estratégias para se pensar as mesmas. Esse artigo buscou apresentar algumas dessas estratégias. Espera-se que os resultados apontados aqui proporcionem outros desenvolvimentos tanto ao prosseguimento dessa pesquisa quanto a outras com as quais venha a dialogar.

\section{REFERÊNCIAS}

BENJAMIN, Walter; OBRAS ESCOLHIDAS I, Magia e Técnica, Arte e Política; Editora Brasiliense; São Paulo, SP, 2012

DELEUZE, Gilles. A ILHA DESERTA E OUTROS TEXTOS, Textos e Entrevistas (1953-1974). Editora lluminuras; São Paulo, SP. 2006 
DELEUZE, Gilles; NIETZSCHE E A FILOSOFIA; n-1 Edições. São Paulo, SP. 2018 HABERMAS, Jürgen; O DISCURSO FILOSÓFICO DA MODERNIDADE; Editora Livraria Martins Fontes Editora; São Paulo, SP; 2000

NIETZSCHE, Friedrich. ALÉM DO BEM E DO MAL, prelúdio a uma filosofia do futuro. São Paulo, SP. Companhia das Letras. 1992

NIETZSCHE, Friedrich. GENEALOGIA DA MORAL. Uma Polêmica. São Paulo, SP. Companhia das Letras. 1999

NIETZSCHE, Friedrich, A GAIA CIÊNCIA. São Paulo, SP. Companhia das Letras. 2011

NIETZSCHE, Friedrich. CREPÚSCULO DOS ÍDOLOS, ou como se filosofa com o martelo. São Paulo, SP. Companhia das Letras. 2013

VATTIMO, Gianni; A SOCIEDADE TRANSPARENTE; Relógio d'Água; Lisboa, Portugal; 1992

VATTIMO, Gianni; O FIM DA MODERNIDADE, Niilismo e Hermenêutica na Cultura Pós-moderna; Editora Livraria Martins Fontes Editora; São Paulo, SP; 1996

VATTIMO, Gianni; DIÁLOGO COM NIETZSCHE, Ensaios 1961-2000; Editora WMF Martins Fontes; São Paulo, SP; 2010 